\title{
A rare complication of endoscopic ligation ("loop-and-let-go") for management of a giant colonic lipoma
}

A 65-year-old man presented with a 6-month history of intermittent lower gastrointestinal bleeding and lower abdominal pain. Colonoscopy revealed a soft, yellowish submucosal tumor measuring around $10 \mathrm{~cm}$ with a short, wide pedicle in the transverse colon ( $\triangleright$ Fig.1a). Endoscopic ultrasonography showed a hyperechoic lesion originating from the submucosal layer ( $\triangleright$ Fig.1 b). As the endoscopic signs were compatible with a colonic lipoma, we performed endoscopic ligation ("loop-and-let-go") to

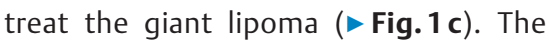
symptoms of bleeding and abdominal pain were relieved. Unfortunately, on the 15 th day after the procedure the patient suffered from severe lower abdominal pain and vomiting. Emergency colonoscopy showed that the shedding tumor was contributing to rectal occlusion ( $\triangleright$ Fig. 1 d), and it was removed from the rectum using oval forceps ( $\$$ Fig.1e; - Video 1).

Colonic lipomas are uncommon benign gastrointestinal subepithelial tumors, with a reported prevalence of $0.3 \%$ [1]. Most colonic lipomas are usually asymptomatic and detected incidentally during colonoscopy. When colonic lipomas become larger or symptomatic, they should be removed [2]. A prospective study demonstrated that the "loop-and-letgo" technique is feasible and safe for re- moval of giant colonic lipomas (ranging in size from $2 \mathrm{~cm}$ to $6 \mathrm{~cm}$ ) because it avoids electrocautery and eliminates the risk of bleeding and perforation [3]. However, in the present case this technique was performed to remove a colonic lipoma as large as $10 \mathrm{~cm}$, and in this patient the shedding tumor contributed to rectal occlusion. We offer this reminder of this possible complication of rectal occlusion when the "loop-and-let-go" technique is employed to remove a giant colonic lipoma.

Endoscopy_UCTN_Code_CPL_1AJ_2AH
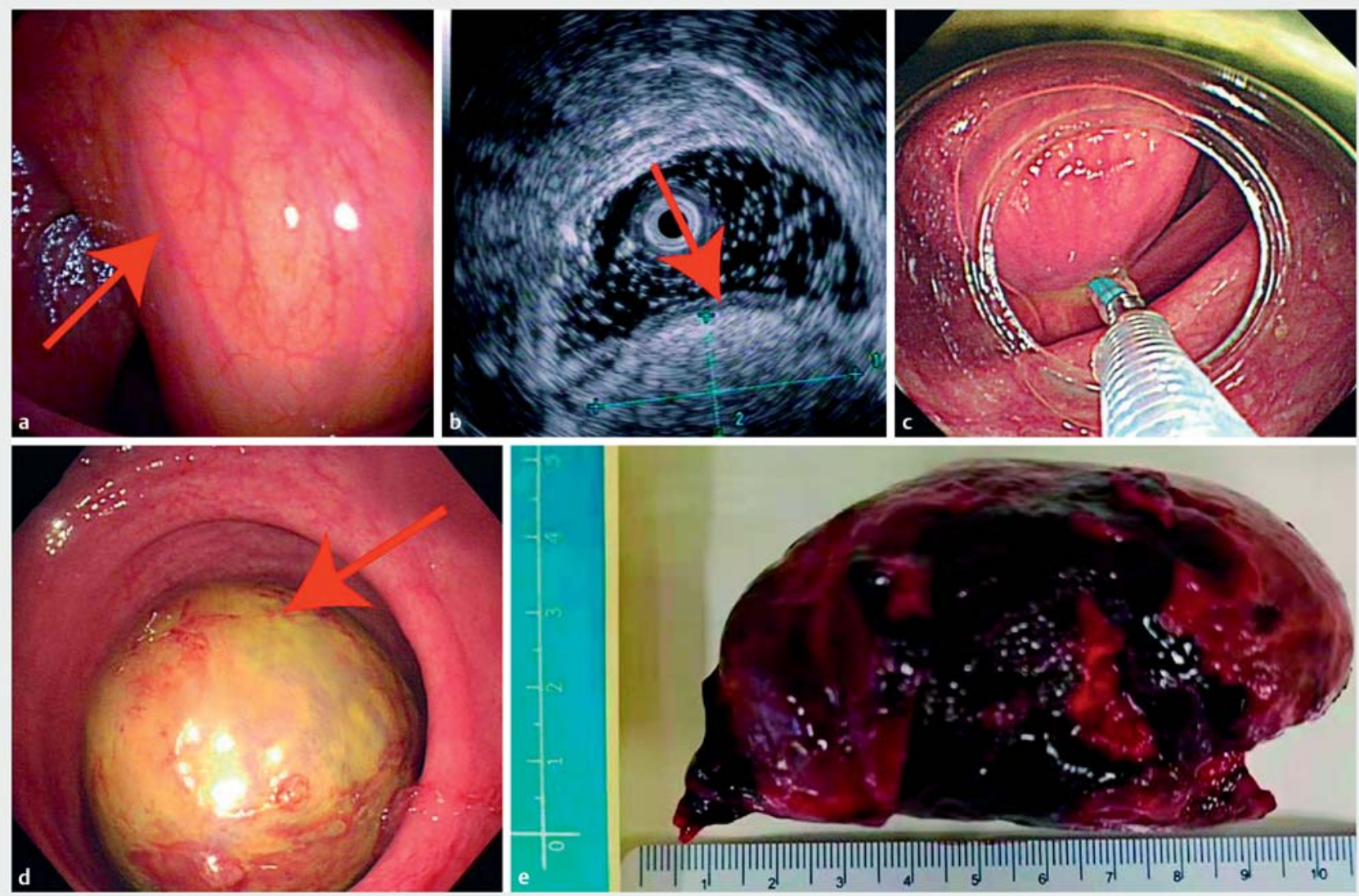

Fig. 1 a A soft, yellowish giant submucosal tumor in the transverse colon; $\mathbf{b}$ a hyperechoic lesion originating from the submucosal layer; c endoscopic ligation ("loop-and-let-go") to treat the giant lipoma; $\mathbf{d}$ the shedding tumor obstructing the rectum; e the shed tumor. 


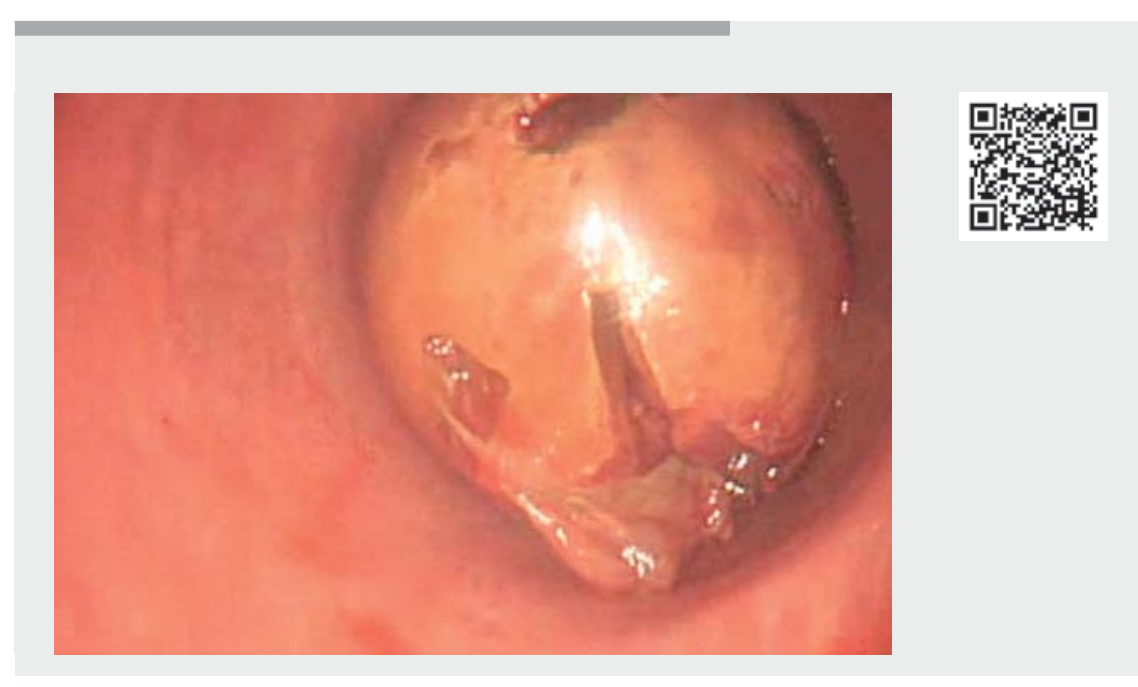

$\checkmark$ Video 1 Removing the shedding tumor from the rectum using oval forceps.

Funding

Technical Research and Development Project of Shenzhen

No.JCYC20170307100911479

Technical Research and Development

Project of Shenzhen

No.JCY|20150403101028164

Technical Research and Development

Project of Shenzhen

No.JCYJ20190807145617113

Three Engineering Training Funds

in Shenzhen

No. SYLY201718

Three Engineering Training Funds

in Shenzhen

No. SYJY201714

Three Engineering Training Funds

in Shenzhen

No. SYLY201801

Natural Science Foundation of Guangdong Province

http://dx.doi.org/10.13039/

501100003453

2018A0303100024

National Natural Science Foundation

of China

http://dx.doi.org/10.13039/

501100001809

No. 81800489
[1] Mantzoros I, Raptis D, Pramateftakis MG et al. Colonic lipomas: our experience in diagnosis and treatment. Tech Coloproctol 2011; 15: S71-S73

[2] Nallamothu G, Adler DG. Large colonic lipomas. Gastroenterol Hepatol 2011; 7: 490492

[3] Ivekovic H, Rustemovic N, Brkic T et al. Endoscopic ligation ("loop-and-let-go") is effective treatment for large colonic lipomas: a prospective validation study. BMC Gastroenterol 2014; 14: 122-126

\section{Bibliography}

Endoscopy 2022; 54: E340-E341

DOI 10.1055/a-1540-6031

ISSN 0013-726X

published online 19.7.2021

(c) 2021. Thieme. All rights reserved.

Georg Thieme Verlag KG, Rüdigerstraße 14, 70469 Stuttgart, Germany

The authors declare that they have no conflict of interest.

\section{ENDOSCOPY E-VIDEOS}

https://eref.thieme.de/e-videos

The authors

De-feng Li ${ }^{*}$, Chao Zheng ${ }^{*}$, Su-zhu Zhu, Li-juan Ye, Ben-hua Wu, Jun Yao Li-sheng Wang Department of Gastroenterology, Shenzhen People's Hospital, Guangdong, P. R. China

\section{Corresponding author}

\section{Jun Yao, MD}

No. 1017, Dongmen North Road, Luohu District, Shenzhen, Guangdong 518020 , P. R. China yj_1108@126.com
Endoscopy E-Videos is an open access online section, reporting on interesting cases and new techniques in gastroenterological endoscopy. All papers include a high quality video and all contributions are freely accessible online. Processing charges apply (currently EUR 375), discounts and wavers acc. to HINARI are available.

This section has its own submission website at

https://mc.manuscriptcentral.com/e-videos

\footnotetext{
${ }^{*}$ These authors contributed equally to this work.
} 